\title{
REDESIGN DE UM DISPOSTIVO PARA AVALIAR AS TENDÊNCIAS DE ENTORSE DE TORNOZELO
}

\section{REDESIGN OF A DEVICE TO EVALUATE SPRAIN ANKLE TENDENCIES}

\author{
Bruna de São Thiago Serpil, Graduanda. \\ Jucelia Salete Giacomini da Silva², Dra. \\ Ivo Coutinho ${ }^{3}$, Me.
} (1) Instituto Federal de Santa Catarina (IFSC)
e-mail: bserpidesign@ gmail.com

(2) Instituto Federal de Santa Catarina (IFSC) e-mail: jucelia.giacomini@ifsc.edu.br

(3) Universidade Politécnica do Porto (IPP) e-mail: ivocoutinho1982@gmail.com

Palavras-chave: dispositivo de saúde, entorse de tornozelo, design de produto

O projeto HEADS consistiu na criação de dispositivos na área da saúde. A oportunidade de projeto estava no problema frequente de entorses de tornozelo em atletas. Assim o objetivo foi o redesign de um dispositivo que analisasse a tendência à torção de tornozelo. Em cooperação com uma equipe multidisciplinar e com enfoque na tecnologia, ergonomia e design, foram projetadas, algumas alternativas de redesign para o dispositivo de entorse.

Key-words in English: health device, sprain ankle, product design

The Heads project consisted in the creation of health related devices. The project opportunity was about sprain ankles in athletes. Thus, this project's aim was to redesign a device that allowed for the analysis of sprain ankle tendencies. In cooperation with a multidisciplinary team, with focus on technology, ergonomics and design, some redesign alternatives for the device were created. 


\section{$16^{\circ}$ \\ ERGODESIGN USIHC CINAHPA}

$16^{\circ}$ Ergodesign - Congresso Internacional de Ergonomia e Usabilidade de Interfaces Humano Tecnológica: Produto, Informações Ambientes Construídos e Transporte

$16^{\circ}$ USIHC - Congresso Internacional de Ergonomia e Usabilidade de Interfaces Humano Computador

CINAHPA | 2017 - Congresso Internacional de Ambientes Hipermídia para Aprendizagem.

\section{Introdução}

O projeto HEADS (Health Devices and Systems) teve início na Porto Design Factory (PDF) em 2015 e atualmente se encontra em etapa de prototipação. A participação desta autora, como intercambista advinda do CST Design de Produto do IFSC no programa, ocorreu no período de março a agosto de 2016 e foi proporcionada pelo programa PROPICIE, Edital no 36/2015/PROPPI, com a parceria estabelecida pelo Instituto Federal de Santa Catarina (IFSC) com o Instituto

Politécnico do Porto (IPP). Este projeto teve como objetivo desenvolver um dispositivo com sensores que proporcionem a análise de tendência à torção de tornozelo em atletas. Tais sensores necessitam ser distribuídos em regiões do corpo do paciente de acordo com as indicações do fisioterapeuta. Assim o fisioterapeuta pode realizar um programa reabilitativo ao paciente de acordo com seu grau de torção.

Para o desenvolvimento deste projeto foi utilizado o método Guia de Orientação para

Desenvolvimento de Projetos (GODP) [MERINO, 2016]. Este método orientou as etapas de trabalho que foram desenvolvidas em cooperação com uma equipe multidisciplinar das áreas de Design,

Fisioterapia, Engenharia Informática, Marketing e Engenharia Eletrônica. Os resultados obtidos neste projeto foram os requisitos do produto, bem como o desenvolvimento de propostas para o redesign do dispositivo de entorse.

\section{Fundamentação Teórica}

O tornozelo é considerado umas das regiões do corpo mais suscetível a lesões durante a atividade esportiva [NUNES; NORONHA; CARVALHO, 2015]. Cerca de $30 \%$ das lesões esportivas são lesões nesta região e a entorse de tornozelo representa $77 \%$ dessas lesões. O fortalecimento muscular e os exercícios proprioceptivos como técnicas efetivas para o tratamento e/ou prevenção das entorses de tornozelo, são métodos para a redução deste tipo de lesão.
Segundo Beirão e Marques (2006), a função biomecânica eficiente do tornozelo depende de sua capacidade de agir como um absorvedor de choques ou impactos, durante o ciclo da marcha. Os movimentos articulares envolvidos, comumente nas lesões do tornozelo e do pé são desencadeados ao caminhar sobre superfícies irregulares, pisar em buracos, rodar o tornozelo durante uma manobra de corte ou aterrar sobre o pé de outro jogador ao descer de um salto nos eventos desportivos [LEÃO, 2002]. As lesões resultantes variam de fratura, luxação a dano ligamentar (entorse). A lesão do ligamento geralmente ocorre no momento do impacto do pé contra o solo. Quando isto ocorre, o pé está em flexão plantar e supinado, o que provoca maior instabilidade óssea do tornozelo. Dentre os tipos de lesões de tornozelo, a inversão é a mais comum, dentre atletas. Afirma Leão (2002), que o termo "entorse" é frequentemente usado em referência específica a lesão de um ligamento, recebendo graduação de entorse de grau I, II e III.

a) Grau I: Envolvimento apenas dos ligamentos laterais;

b) Grau II: Envolvimento tanto dos ligamentos mediais quanto dos laterais;

c) Grau III: Envolvimento dos ligamentos laterais e mediais e do pseudoarticular tibiofibular (interósseo) distal.

Na Figura 1 observa-se os tipos de torções existentes, inversão e eversão.

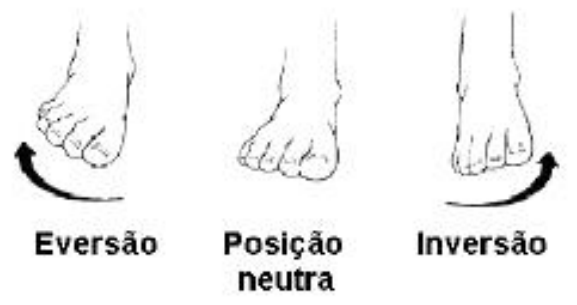

Figura 1: Inversão de tornozelo Fonte: Blumm (2015)

A partir dos estudos realizados sobre os tipos de entorse de tornozelo, o modo como elas ocorrem, o número elevado de casos de entorses entre atletas, os testes realizados com o protótipo Trapdoor em
Realização:

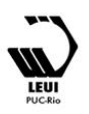




\section{$16^{\circ}$ \\ ERGODESIGN USIHC CINAHPA}

paralelo com as explicações dos fisioterapeutas sobre o mecanismo de entorse, foi possível entender a situação pelo qual os atletas passam ao torcer o tornozelo assim como o trabalho que o fisioterapeuta deve realizar para auxiliar o seu paciente. Permitindo que durante a geração de alternativas fossem considerados os ângulos limiares para ocorrer a torção, assim como as formas e geometrismo que auxiliam o trabalho do fisioterapeuta e não prejudicam o paciente.

\section{Análise de usuários, produto e contexto}

De acordo com o método GODP, as informações coletadas durante o projeto foram segmentadas em três blocos de referência: usuário, contexto e produto. O quadro 1 , sobre usuários, mostra $\mathrm{o}$ público-alvo definido através de estudos preliminares da Escola Superior de Tecnologia da Saúde do Porto (ESTSP) através de teses sobre entorse de tornozelo, com o conhecimento de fisioterapeutas e de estudos experimentais com jogadores de futebol do Porto, Portugal. Foram realizadas pesquisas complementares a respeito dos esportes com maior incidência de entorse de tornozelo, futebol, voleibol e basquetebol [LEÃO, 2011]. Assim foi possível definir as dimensões que o dispositivo de entorse deve apresentar para comportar o tamanho dos pés dos jogadores, bem como em quais superfícies os jogadores costumam praticar o esporte, conforme quadro 1.

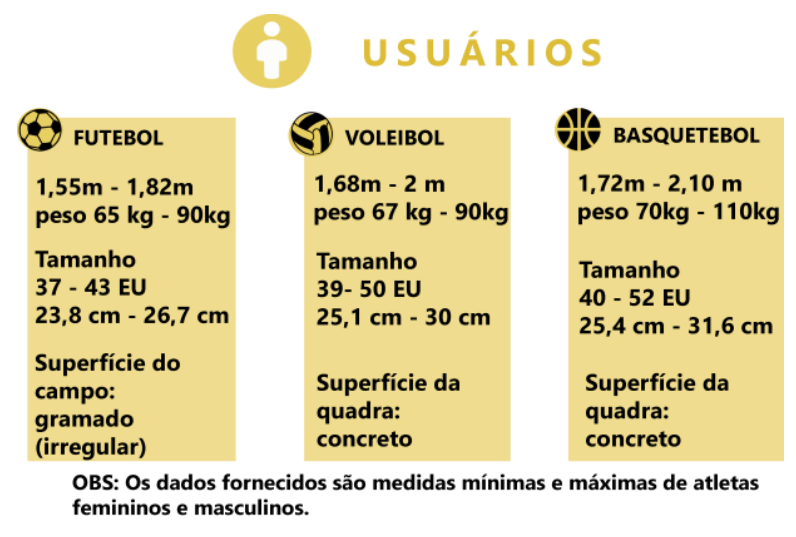

De acordo com as pesquisas anteriores realizadas pela ESTSP, foi definido que as clínicas de fisioterapia seriam as principais interessadas no resultado do projeto (quadro 2).

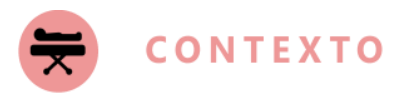

CLÍNICAS DE FISIOTERAPIA
Permite a verificação
de entorses e lesões
semelhantes.
Oferece condições únicas de
avalição de lesões:
entorse grau I
entorse grau II
entorse grau III

PORTÁTIL
Permite a realização de testes
no clube ou até mesmo em
casa.
Para usuários indiretos:
facilita a higienização
e o transporte
intra-instalações.

Quadro 2: Contexto de uso do produto Fonte: Autoria própria.

A necessidade deste produto em clínicas de fisioterapia está relacionada com o propósito de existência do produto, ou seja, a verificação de entorses e lesões análogas, além da frequência e impacto nos atletas.

Assim, os atletas serão orientados pelo seu técnico para se dirigir a uma clínica de fisioterapia que possua o equipamento. O produto deve ser portátil para permitir a sua utilização em mais do que um local além de facilitar a higienização do produto e o transporte intra-instalações.

No quadro 3 foram sintetizadas as funções que o produto deverá ter, as propriedades dos materiais de produtos hospitalares, informações sobre lesões de tornozelo, bem como informações sobre impressão 3D no ramo da Saúde.

Quadro 1: Síntese sobre os usuários Fonte: Autoria própria. 
$16^{\circ}$

\section{ERGODESIGN USIHC CINAHPA}

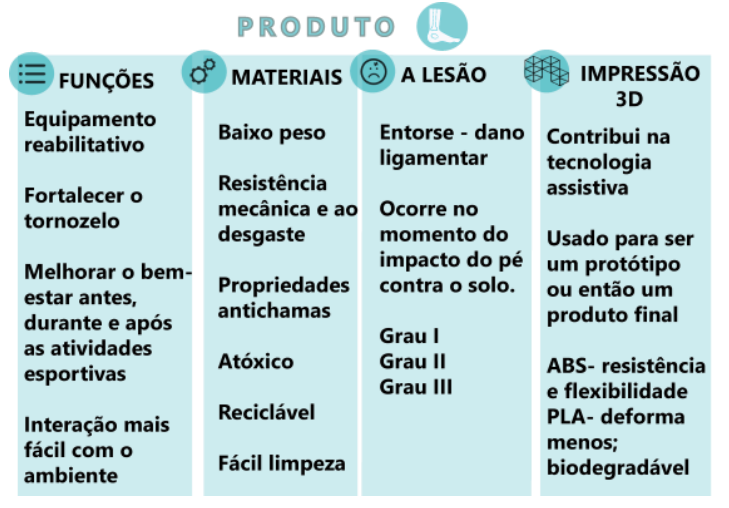

Quadro 3: Síntese sobre produto

Fonte: Autoria própria.

\section{Desenvolvimento do produto}

Para o projeto HEADS, o brainstorming foi realizado com bolsistas e professores da PDF, das áreas de Design, Engenharia Informática, Marketing e Eletrotécnica. A ferramenta brainstorming consiste na reunião de um grupo de pessoas para lançar várias ideias com a finalidade de solucionar um problema em especifico. Nesta sessão de brainstorming ideias simples e complexas foram discutidas a fim de estabelecer as possibilidades de redesign do dispositivo do projeto. Como a equipe era multidisciplinar, foram geradas ideias relacionadas a diferentes escopos do projeto. Ideias como: a modularidade do produto, facilitando a portabilidade; utilização de cores sóbrias, remetendo a ambientes hospitalares; ter queda de plataformas com tempo programado, para haver efeito surpresa para o atleta; dentre outras. O protótipo (Figuras 2 e 3 ) do dispositivo para entorse de tornozelo foi desenvolvido pela equipe de participantes do HEADS no início de 2015, o qual foi denominado de Trapdoor e se encontra na ESTSP. Estudos sobre Goniometria, técnica para medir ângulos muito usada por fisioterapeutas de inversão de tornozelo (CHICHON, 2004), indicam que o mínimo da amplitude do movimento do tornozelo é de $15^{\circ}$ e o máxima em torno de $32^{\circ}$, conforme membro dominante ou não dominante. De acordo com os fisioterapeutas da ESTSP, o redesign do protótipo Trapdoor deveria ter no máximo um ângulo de $30^{\circ}$ de amplitude para a $16^{\circ}$ Ergodesign - Congresso Internacional de Ergonomia e Usabilidade de Interfaces Humano Tecnológica: Produto, Informações Ambientes Construídos e Transporte

$16^{\circ}$ USIHC - Congresso Internacional de Ergonomia e Usabilidade de Interfaces Humano Computador

CINAHPA | 2017 - Congresso Internacional de Ambientes Hipermídia para Aprendizagem.

queda das plataformas, não havendo a inversão de tornozelo e aprimorando a ergonomia do protótipo, adaptando assim o produto às limitações do atleta.

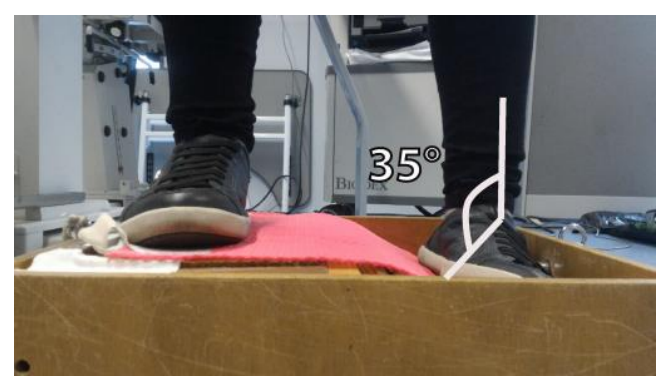

Figura 2: Trapdoor e Goniometria Fonte: Autoria própria.

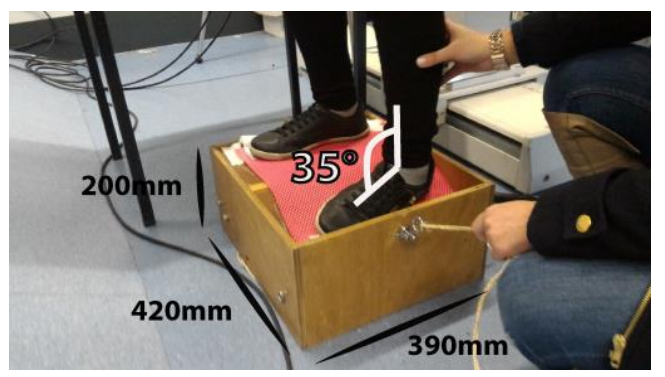

Figura 3: Trapdoor e Ergonomia Fonte: Autoria própria.

O protótipo Trapdoor, assemelha-se a uma caixa, a qual possui duas plataformas que caem conforme o fisioterapeuta puxa manualmente a corda na lateral do protótipo. $\mathrm{O}$ ângulo da amplitude do movimento do tornozelo foi de $35^{\circ}$, o que causou ao usuário uma leve dor no tornozelo horas após o teste.

Sendo que o ângulo indicado pelos fisioterapeutas é de $30^{\circ}$ para o segundo protótipo a ser realizado a partir do redesign do Trapdoor. Assim provavelmente não causará dores ao usuário que participará do teste. De acordo com os fisioterapeutas da ESTSP, o efeito surpresa para o atleta, de queda das plataformas é fundamental para a avaliação da tendência de entorse do atleta. Pois se o atleta souber que as plataformas irão cair efetuará um tensionamento dos músculos relacionados ao tornozelo, podendo machucar-se ou alterar os resultados obtidos através dos sensores acoplados no seu corpo.
Realização:

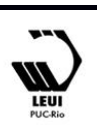




\section{$16^{\circ}$ \\ ERGODESIGN USIHC CINAHPA}

\section{Resultados}

Com base na pesquisa realizada e nos dados apresentados foram definidos os requisitos de projeto segmentados nos blocos de informação: produto, usuário e contexto.

A atividade de definição de requisitos foi realizada com a equipe multidisciplinar presente no brainstorming e envolvida no projeto HEADS. Nesta etapa toda a equipe analisou os requisitos considerados mais importantes e quais não eram essenciais para o redesign do dispositivo.

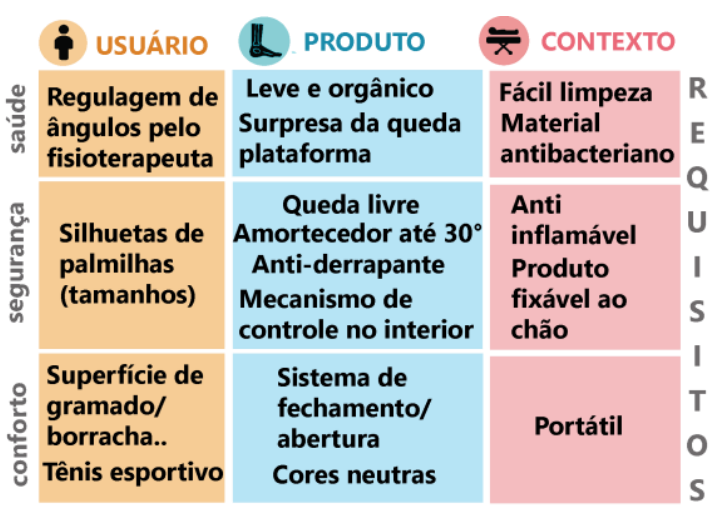

Quadro 4: Requisitos de projeto

Fonte: Autoria própria.

A partir dos requisitos estabelecidos e

categorizados no Quadro 4, iniciou-se a geração de alternativas. Deste modo foi realizado estudo para o redesign do Trapdoor existente, de maneira que a ergonomia e estética do produto fossem aprimoradas.

Na Figura 4, a alternativa contém um sistema elétrico de queda das plataformas com efeito surpresa com ângulo máximo de $30^{\circ}$,

compartimento interior para mecanismo elétrico, plataformas com silhuetas para localização dos pés, alças e rodinhas para melhor portabilidade, design orgânico e cores neutras. $16^{\circ}$ Ergodesign - Congresso Internacional de Ergonomia e Usabilidade de Interfaces Humano Tecnológica: Produto, Informações Ambientes Construídos e Transporte

$16^{\circ}$ USIHC - Congresso Internacional de Ergonomia e Usabilidade de Interfaces Humano Computador

CINAHPA | 2017 - Congresso Internacional de Ambientes Hipermídia para Aprendizagem.

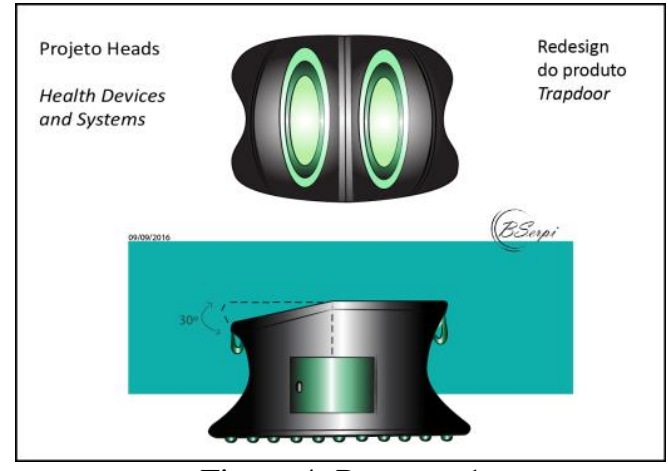

Figura 4: Proposta 1

Fonte: Autoria própria.

A Figura 5 apresenta a alternativa que contém um sistema elétrico de queda das plataformas com efeito surpresa com ângulo máximo de $30^{\circ}$, compartimento interior para mecanismo elétrico, plataformas com silhuetas para localização dos pés.

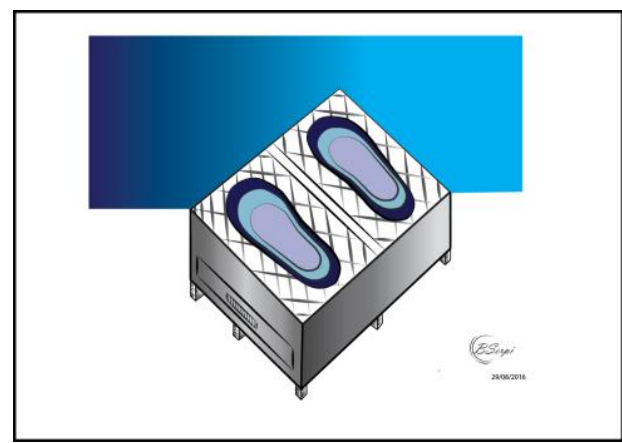

Figura 5: Proposta 2

Fonte: Autoria própria.

As Figuras 6 e 7 representam um sistema elétrico de queda das plataformas com efeito surpresa programado pelo fisioterapeuta, com ângulo máximo de $30^{\circ}$, amortecimento de molas/borracha, compartimento interior para mecanismo elétrico, plataformas com silhuetas para localização dos pés, design orgânico e cores neutras. 


\section{$16^{\circ}$ \\ ERGODESIGN USIHC CINAHPA}

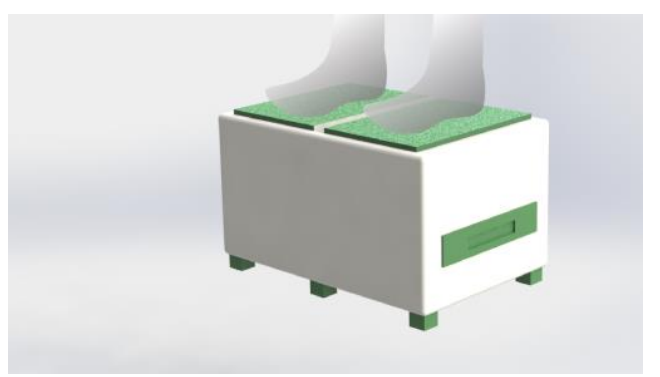

Figura 6: Proposta 3

Fonte: Autoria própria.

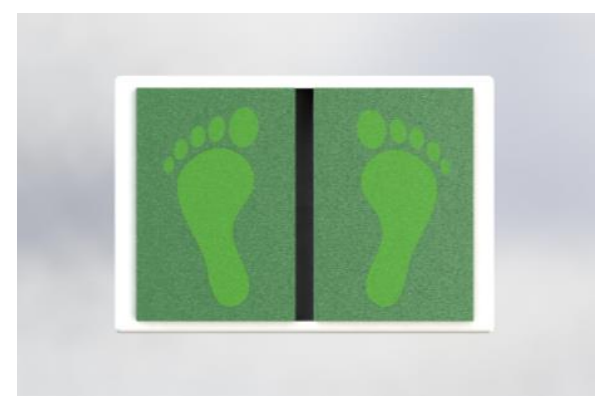

Figura 7: Proposta 3, vista superior Fonte: Autoria própria.

O projeto Heads está ainda em desenvolvimento pela equipe da PDF e está em fase de prototipagem do segundo protótipo Trapdoor realizado a partir das propostas de redesign feitas pela autora.

\section{Conclusões}

A análise de tendência à torção de tornozelo do atleta, juntamente de sensores, auxiliará o fisioterapeuta a realizar um programa reabilitativo personalizado ao paciente de acordo com seu grau de torção. Garantindo o bem-estar dos atletas.

Além de proporcionar um meio eficaz de avaliação e seleção usado por diretores de equipes de futebol, vôlei, dentre outros esportes, para julgar se o investimento em um atleta será positivo ou não, de acordo com a probabilidade de entorse de tornozelo. Um projeto de produto requer um domínio das noções básicas de ergonomia, para melhorar a interação entre usuário e produto. $\mathrm{O}$ atendimento aos requisitos ergonômicos possibilita aumentar a satisfação e o bem-estar, a prevenção de futuros danos ao corpo, além de garantir a segurança do usuário. O uso da ergonomia também aperfeiçoa o desempenho da tarefa, o rendimento $16^{\circ}$ Ergodesign - Congresso Internacional de Ergonomia e Usabilidade de Interfaces Humano Tecnológica: Produto, Informações Ambientes Construídos e Transporte

$16^{\circ}$ USIHC - Congresso Internacional de Ergonomia e Usabilidade de Interfaces Humano Computador

CINAHPA | 2017 - Congresso Internacional de Ambientes Hipermídia para Aprendizagem.

do trabalho e a produtividade do sistema usuáriotarefa-produto.

\section{Referências Bibliográficas}

BEIRÃO, Marcelo Emilio; MARQUES, Thiago Álvaro R.. Estudo dos fatores desencadeantes do entorse do tornozelo em jogadores de futebol e elaboração de um programa de fisioterapia preventiva. 2006. Disponível em:

<http://periodicos.unesc.net/saude/article/viewFile/ 6/4>. Acesso em: 11 abr. 2016.

\section{BLUMM, Ana Carolina Nerva. Análise do} ambiente mercadológico e tecnológico para a definição de especificações-meta e conceito de uma prótese transtibial. 2015. Disponível em: $<$ http://bdm.unb.br/bitstream/10483/13662/6/2015 _AnaCarolinaNervaBlumm.pdf $>$. Acesso em: 17 fev. 2017.

CHICHON, Elisangela de Fatima. Analise das alterações de força e amplitude de movimento de tornozelo de atletas de futebol de campo com entorse de tornozelo. $2004.79 \mathrm{f}$. TCC

(Graduação) - Curso de Fisioterapia, Tuiuti do Paraná, Curitiba, 2004. Disponível em:

<http://tcconline.utp.br/wpcontent/uploads/2012/09/ANALISE-DAS-

ALTERACOES-DE-FORCA-E-AMPLITUDEDE-MOVIMENTO-DE-TORNOZELO-EMATLETAS-DE-FUTEBOL-DE-CAMPO-COMENTORSE-DE-TORNOZELO.pdf $>$. Acesso em: 11 jan. 2017.

\section{LEÃO, Sônia Rabelo Gomes. A incidência de} entorse de tornozelo no esporte: Uma revisão de literatura. 2002. Disponível em:

<http://portalbiocursos.com.br/ohs/data/docs/32/67 $-$

_A_incidYncia_de_entorse_de_tornozelo_no_espo rte_-_uma_revisYo_de_literatura.pdf $>$. Acesso em: 


\section{$16^{\circ}$ \\ ERGODESIGN USIHC CINAHPA}

$16^{\circ}$ Ergodesign - Congresso Internacional de Ergonomia e Usabilidade de Interfaces Humano Tecnológica: Produto, Informações Ambientes Construídos e Transporte

$16^{\circ}$ USIHC - Congresso Internacional de Ergonomia e Usabilidade de Interfaces Humano Computador

CINAHPA | 2017 - Congresso Internacional de Ambientes Hipermídia para Aprendizagem.

11 abr. 2016.

MERINO, Giselle Schmidt Alves Díaz. GODP Guia de Orientação para Desenvolvimento de Projetos: Uma metodologia de design centrado no usuário. 2016. Disponível em:

$<$ http://www.ngd.ufsc.br/files/2016/07/e-bookgodp.pdf >. Acesso em: 03 mar. 2017.

NUNES, Guilherme S.; NORONHA, Marcos de; CARVALHO JUNIOR, Vanderlei A. de. Imagética motora no tratamento da entorse lateral de tornozelo em atletas de futebol de campo: um estudo piloto. Fisioterapia e Pesquisa, São Paulo, v. 22, n. 3, p.100-110, jul. 2015. Disponível em: <http://www.scielo.br/scielo.php?script=sci_arttext \&pid=S1809-29502015000300282\&lang=pt $>$. Acesso em: 28 mar. 2016. 